\title{
Dopamine Transporter Endocytic Trafficking in Striatal Dopaminergic Neurons: Differential Dependence on Dynamin and the Actin Cytoskeleton
}

\author{
Luke R. Gabriel, ${ }^{2}$ Sijia Wu, ${ }^{2}$ Patrick Kearney, ${ }^{1}$ Karl D. Bellvé, ${ }^{3}$ Clive Standley, ${ }^{3}$ Kevin E. Fogarty, ${ }^{3}$ and Haley E. Melikian \\ Brudnick Neuropsychiatric Research Institute, ${ }^{1}$ Department of Psychiatry, ${ }^{2}$ Neuroscience Graduate Program, Graduate School of Biomedical Sciences, and \\ ${ }^{3}$ Program in Molecular Medicine, Biomedical Imaging Group, University of Massachusetts Medical School, Worcester, Massachusetts 01655
}

\begin{abstract}
Dopaminergic signaling profoundly impacts rewarding behaviors, movement, and executive function. The presynaptic dopamine (DA) transporter (DAT) recaptures released DA, thereby limiting synaptic DA availability and maintaining dopaminergic tone. DAT constitutively internalizes and PKC activation rapidly accelerates DAT endocytosis, resulting in DAT surface loss. Longstanding evidence supports PKC-stimulated DAT trafficking in heterologous expression studies. However, PKC-stimulated DAT internalization is not readily observed in cultured dopaminergic neurons. Moreover, conflicting reports implicate both classic and nonclassic endocytic mechanisms mediating DAT trafficking. Prior DAT trafficking studies relied primarily upon chronic gene disruption and dominantnegative protein expression, or were performed in cell lines and cultured neurons, yielding results difficult to translate to adult dopaminergic neurons. Here, we use newly described dynamin inhibitors to test whether constitutive and PKC-stimulated DAT internalization are dynamin-dependent in adult dopaminergic neurons. Ex vivo biotinylation studies in mouse striatal slices demonstrate that acute PKC activation drives native DAT surface loss, and that surface DAT surprisingly partitions between endocytic-willing and endocytic-resistant populations. Acute dynamin inhibition reveals that constitutive DAT internalization is dynamin-independent, whereas PKC-stimulated DAT internalization is dynamin-dependent. Moreover, total internal reflection fluorescence microscopy experiments demonstrate that constitutive DAT internalization occurs equivalently from lipid raft and nonraft microdomains, whereas PKC-stimulated DAT internalization arises exclusively from lipid rafts. Finally, DAT endocytic recycling relies on a dynamin-dependent mechanism that acts in concert with the actin cytoskeleton. These studies are the first comprehensive investigation of native DAT trafficking in ex vivo adult neurons, and reveal that DAT surface dynamics are governed by complex multimodal mechanisms.
\end{abstract}

\section{Introduction}

Dopamine (DA) neurotransmission is obligatory for movement, and the dopaminergic circuitry is intimately coupled to rewarding behavior (Hyman et al., 2006) and cognitive function (Lyon et al., 2011). DA's extracellular half-life and neuronal DAergic tone are determined by DA transporter (DAT)-mediated presynaptic reuptake. DAT is an SLC6 solute carrier robustly expressed in substantia nigra and ventral tegmental area dopaminergic neurons (Amara et al., 1998; Kristensen et al., 2011; Bröer and Gether, 2012). Multiple therapeutic and addictive drugs potently inhibit DAT, including methylphenidate (ritalin), NDRI antidepressants, amphetamine (AMPH), and cocaine (Gether et al., 2006). Investigations using a cocaine-insensitive DAT knock-in mouse demonstrated that cocaine reward absolutely requires

\footnotetext{
Received July 2, 2013; revised Sept. 17, 2013; accepted Oct. 6, 2013.

Author contributions: L.R.G., S.W., K.D.B., C.S., and H.E.M. designed research; L.R.G., S.W., and P.K. performed research; K.D.B. and C.S. contributed unpublished reagents/analytic tools; L.R.G., S.W., K.E.F., and H.E.M. analyzed data; L.R.G., K.E.F., and H.E.M. wrote the paper.

This work was supported by NIH Grants DA15169 and DA035224 (H.E.M.).

Correspondence should be addressed to Dr Haley E. Melikian, Brudnick Neuropsychiatric Research Institute, Department of Psychiatry, University of Massachusetts Medical School, 303 Belmont Street, Worcester, MA 01604. E-mail: haley.melikian@umassmed.edu.

DOI:10.1523/JNEUROSCI.3284-13.2013

Copyright $\odot 2013$ the authors $\quad 0270-6474 / 13 / 3317836-11 \$ 15.00 / 0$
}

DAT inhibition (Thomsen et al., 2009; Tilley et al., 2009). In addition to its role as a pharmacological target several DAT coding variants are reported in attention-deficit hyperactivity disorder (ADHD; Mazei-Robison and Blakely, 2005; Mazei-Robison et al., 2008; Bowton et al., 2010; Sakrikar et al., 2012) and autism spectrum disorder (Hamilton et al., 2013) patients. Additionally, DAT dysfunction downstream of CaMKII anomalies occurs in an Angelman syndrome mouse model (Steinkellner et al., 2012).

Given DAT's critical role in normal neurotransmission, as a drug target and in dopaminergic pathologies, cellular mechanisms modulating DAT availability are likely to significantly impact behavior and overall homeostasis. Longstanding evidence supports that DAT surface presentation is highly plastic and is subject to regulated endocytic trafficking (Torres et al., 2003; Melikian, 2004). DAT constitutively internalizes and recycles, and protein kinase $\mathrm{C}$ activation rapidly accelerates DAT internalization rates, resulting in acute DAT surface loss. Moreover a DAT coding variant in an ADHD patient encodes a carboxyterminal point mutation that results in anomalously rapid DAT endocytosis (Sakrikar et al., 2012), suggesting that regulated DAT trafficking may profoundly influence executive function.

Significant effort has been directed at deciphering the mechanisms that dictate DAT endocytic trafficking. Several studies 
implicate classic clathrin-dependent endocytic machinery (Daniels and Amara, 1999; Sorkina et al., 2005), whereas other studies suggest that clathrin-independent mechanisms facilitate DAT internalization (Holton et al., 2005; Boudanova et al., 2008b; Cremona et al., 2011). Moreover, several reports indicate that DAT targets to degradative pathways following internalization (Daniels and Amara, 1999; Miranda et al., 2005; Eriksen et al., 2010), whereas other reports suggest that DAT traffics via the endocyticrecycling pathway (Loder and Melikian, 2003; Boudanova et al., 2008b; Furman et al., 2009). DAT internalization studies have been performed in various neuronal, neuroendocrine, and nonneuronal cell lines, as well as in rodent synaptosomes and primary ventral midbrain cultures, raising concerns regarding which studies reflect native DAT endocytic mechanisms. Moreover, many studies chronically disrupt classic clathrin- and dynamin-dependent endocytic trafficking, which could potentially have deleterious effects throughout the biosynthetic pathway. Here, we capitalize on newly developed pharmacological tools to test whether constitutive and PKC-regulated DAT internalization are dynamin-dependent ex vivo in adult mouse striatum. Our results suggest that DAT internalization and recycling are differentially dependent upon dynamin and the actin cytoskeleton. Moreover, the endocytic capacity of surface DAT functionally partitions into distinct populations that are membrane raft independent.

\section{Materials and Methods}

Materials. pTagRFP-T-C1 vector was a generous gift from Dr Silvia Corvera (University of Massachusetts Medical School, Worcester, Massachusetts) and hDAT cDNA was cloned into pTagRFP-T-C1 in frame at the HindIII/XbaI sites. Rat anti-DAT (MAB369) and mouse antityrosine hydroxylase (TH) antibodies were from Millipore. Mouse antitransferrin receptor (TfR) antibody (H68.4), Tf-Alexa594 and cholera toxin subunit B-Alexa488 were from Invitrogen. Mouse anti-actin antibodies and HRP-conjugated secondary antibodies were from Santa Cruz Biotechnology. Dynasore, dynoles, and phorbol 12-myristate 13-acetate (PMA) were from Tocris Bioscience. Sulfo-NHS-SS-biotin and streptavidin agarose were from Pierce Biotechnology. Dihydroxyphenylethylamine, 3, 4-[Ring-2, 5, 6- $\left.{ }^{3} \mathrm{H}\right]$ dopamine and $\mathrm{L}-\left[{ }^{3} \mathrm{H}\right]$ alanine were from PerkinElmer. Monensin, cytochalasin D (CytoD) and reagents used for ACSF were from Sigma-Aldrich. All other reagents were from Fisher Scientific or Sigma-Aldrich and were of highest quality possible.

Cell culture. The human neuroblastoma cell line SK-N-MC were maintained in MEM (Sigma-Aldrich, no. M2279) supplemented with 10\% fetal bovine serum (Invitrogen), $2 \mathrm{~mm} \mathrm{~L}$-glutamine and $100 \mathrm{Us} / \mathrm{ml}$ penicillin/streptomycin at $37^{\circ} \mathrm{C}, 5 \% \mathrm{CO}_{2}$. Pooled, stable SK-N-MC cell lines expressing either hDAT or a TagRFP-T-hDAT fusion protein (Tag-RFPT-DAT) were generated by transfecting $1 \times 10^{6}$ cells/well in 6-well culture plates with $3 \mu \mathrm{g}$ plasmid DNA using Lipofectamine 2000, at lipid: DNA ratio of 2:1 (w/w). Stably transformed cells were selected with 0.4 $\mathrm{mg} / \mathrm{ml}$ geneticin (G418, Invitrogen) and resistant cells were pooled and

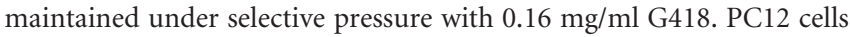
stably expressing hDAT were cultured as previously described (Loder and Melikian, 2003) at $37^{\circ} \mathrm{C}, 10 \% \mathrm{CO}_{2}$ in DMEM supplemented with $5 \%$ bovine calf serum, $5 \%$ horse serum, 2 mM L-glutamine, $100 \mathrm{Us} / \mathrm{ml}$ penicillin/streptomycin, $0.2 \mathrm{mg} / \mathrm{ml} \mathrm{G} 418$.

Uptake assays. DAT-PC12 cells were seeded onto poly-D-lysine-coated 24 -well plates at a density of $2 \times 10^{5} /$ well $24 \mathrm{~h}$ before performing assays. Cells were rinsed twice with Krebs-Ringer-HEPES (KRH) buffer (120 mм NaCl, $4.7 \mathrm{~mm} \mathrm{KCl}, 2.2 \mathrm{~mm} \mathrm{CaCl}_{2}, 1.2 \mathrm{~mm} \mathrm{MgSO}_{4}, 1.2 \mathrm{~mm} \mathrm{KH}_{2} \mathrm{PO}_{4}$, $0.18 \%$ glucose, and $10 \mathrm{~mm}$ HEPES, $\mathrm{pH} 7.4$ ) and incubated in $\mathrm{KRH} /$ $0.18 \%$ glucose, $37^{\circ} \mathrm{C}$ for indicated times with the indicated drugs. For DA transport, assays were initiated by adding $1 \mu \mathrm{M}\left[{ }^{3} \mathrm{H}\right] \mathrm{DA}$ in KRH supplemented with $10^{-5} \mathrm{M}$ each pargyline and ascorbic acid. For $\mathrm{Na}^{+}$dependent alanine transport, assays were initiated by adding $500 \mu \mathrm{M}$ $\mathrm{L}-\left[{ }^{3} \mathrm{H}\right]$ alanine. Assays proceeded for $10 \mathrm{~min}, 37^{\circ} \mathrm{C}$, and were terminated by rapidly washing cells with ice-cold KRH buffer. Cells were solubilized in scintillation fluid, and accumulated radioactivity was determined by liquid scintillation counting in a Wallac MicroBeta scintillation plate counter. Nonspecific DA uptake was defined in the presence of $10 \mu \mathrm{M}$ GBR12909 and all samples included $100 \mathrm{~nm}$ desipramine to block uptake contribution by endogenously expressed norepinephrine transporters. Nonspecific alanine uptake was defined in parallel in $\mathrm{Na}^{+}$-free $\mathrm{KRH}$ buffer prepared with $120 \mathrm{~mm}$ choline chloride. Data were analyzed using GraphPad Prism software.

Cell surface biotinylation. Cells were seeded onto 6-well plates $24 \mathrm{~h}$ before performing assays at densities of $1.6 \times 10^{6} /$ well (DAT-SK-N-MC) or $1.5 \times 10^{6} /$ well (DAT-PC12. DAT-PC12 cells were seeded on poly-Dlysine-coated plates. Cells were treated with the indicated drugs for the indicated times and surface proteins were covalently labeled with sulfo NHS-SS-biotin as previously described (Loder and Melikian, 2003; Holton et al., 2005). Briefly, cells were washed and rapidly chilled in ice-cold PBS, pH 7.4, supplemented with $1.0 \mathrm{~mm} \mathrm{MgCl}_{2}, 0.1 \mathrm{mM} \mathrm{CaCl}_{2}\left(\mathrm{PBS}^{2+}\right)$, and incubated with $1.0 \mathrm{mg} / \mathrm{ml}$ sulfo-NHS-SS-biotin in ice-cold $\mathrm{PBS}^{2+}$ twice for $15 \mathrm{~min}$ at $4^{\circ} \mathrm{C}$. Residual reactive biotin was quenched with two incubations in $\mathrm{PBS}^{2+} / 100 \mathrm{~mm}$ glycine, $15 \mathrm{~min}, 4^{\circ} \mathrm{C}$. Cells were washed three times in ice-cold $\mathrm{PBS}^{2+}$, were lysed in RIPA buffer containing protease inhibitors and protein concentrations were determined using the BCA protein assay (Pierce). Biotinylated proteins were isolated by batch streptavidin chromatography (overnight, $4^{\circ} \mathrm{C}$ ) and bound proteins were eluted in SDS-PAGE sample buffer. Total lysate samples were stored in SDS-PAGE sample buffer, $-20^{\circ} \mathrm{C}$ until analysis. Samples were resolved by SDS-PAGE and specific proteins were detected by immunoblotting with the indicated antibodies. Immunoreactive bands were detected with SuperSignal West Dura (Pierce) and were captured using a VersaDoc Imaging station (Biorad). Nonsaturating bands were quantified using Quantity One software (Biorad).

Striatal slice biotinylation. All animals were handled in accordance with University of Massachusetts Medical School IACUC protocol A1506 (H.E.M.). P21-P38 male C57/B6 mice were killed by cervical dislocation and decapitated. The brains were removed and immediately chilled in sucrose-supplemented artificial CSF (SACSF; $2.5 \mathrm{~mm} \mathrm{KCl,} 1.2 \mathrm{~mm}$ $\mathrm{NaH}_{2} \mathrm{PO}_{4}, 1.2 \mathrm{~mm} \mathrm{MgCl} 2,2.4 \mathrm{~mm} \mathrm{CaCl}, 26 \mathrm{~mm} \mathrm{NaHCO}_{3}, 11 \mathrm{~mm}$ glucose, and $250 \mathrm{~mm}$ sucrose) saturated with $95 \% \mathrm{O}_{2} / 5 \% \mathrm{CO}_{2}$. Brains were mounted on a vibratome 1500 sectioning system and $300 \mu \mathrm{m}$ coronal sections were made. Sections containing striatum were recovered in ACSF ( $125 \mathrm{~mm} \mathrm{NaCl}, 2.5 \mathrm{~mm} \mathrm{KCl}, 1.2 \mathrm{~mm} \mathrm{NaH}_{2} \mathrm{PO}_{4}, 1.2 \mathrm{~mm} \mathrm{MgCl}_{2}, 2.4$ $\mathrm{mm} \mathrm{CaCl}, 26 \mathrm{~mm} \mathrm{NaHCO}_{3}$, and $11 \mathrm{~mm}$ glucose), $31^{\circ} \mathrm{C}, 40 \mathrm{~min}$ with $95 \% \mathrm{O}_{2} / 5 \% \mathrm{CO}_{2}$, then were immediately used for trafficking studies. Slices were treated with the indicated drugs for the indicated times with $95 \% \mathrm{O}_{2} / 5 \% \mathrm{CO}_{2}$. Surface proteins were covalently labeled with $1.0 \mathrm{mg} / \mathrm{ml}$ sulfo-NHS-SS-biotin in ice-cold ACSF, $45 \mathrm{~min}, 4^{\circ} \mathrm{C}$, with bubbling $95 \% \mathrm{O}_{2} / 5 \% \mathrm{CO}_{2}$. Following biotinylation, slices were washed twice in ice-cold ACSF and three times in ice-cold ACSF supplemented with 100 $\mathrm{mm}$ glycine. Residual reactive biotin was quenched by incubating twice in ice-cold ACSF supplemented with glycine, $20 \mathrm{~min}, 4^{\circ} \mathrm{C}$, with bubbling $95 \% \mathrm{O}_{2} / 5 \% \mathrm{CO}_{2}$. And slices were washed four times with ice-cold ACSF. Tissue was lysed by triturating in RIPA buffer several times through a P200 pipette tip and rotating $30 \mathrm{~min}, 4^{\circ} \mathrm{C}$. Cellular debris was cleared by centrifugation at $18,000 \times \mathrm{g}, 20 \mathrm{~min}, 4^{\circ} \mathrm{C}$ and protein concentrations were determined using the BCA protein assay. Biotinylated proteins were isolated and analyzed as described for cells lines, above. A bead:lysate ratio of $40 \mu \mathrm{l}$ streptavidin agarose: $20 \mu \mathrm{g}$ striatal lysate was empirically determined optimal to quantitatively recover all biotinylated DAT.

TIRF colocalization studies. SK-N-MC cells stably expressing TagRFPT-DAT were treated with the indicated drugs for the indicated times, $37^{\circ} \mathrm{C}$ and were rapidly chilled by washing three times in ice-cold PBS. Cells were incubated with $0.2 \mu \mathrm{g} / \mathrm{ml}$ Alexa488-cholera toxin subunit B (CTX), $45 \mathrm{~min}, 4^{\circ} \mathrm{C}$, washed three times in PBS and fixed in $4 \%$ paraformaldehyde, $10 \mathrm{~min}$, at room temperature. Total internal reflection fluorescence (TIRF) images in the red and green channels were captured using the TESM microscope (Bioimaging Group, University of Massachusetts Medical School) as described by Navaroli et al., (2012). Briefly, images of through-the-lens TIRF were generated using $491 \mathrm{~nm}$ (Alexa488-CTX) and $561 \mathrm{~nm}$ (TagRFP-T-DAT) laser illumination to- 
gether with a 1.49 NA objective lens (Olympus). Stack of optical sections were acquired at $100 \mathrm{~nm} z$-spacing. CTX and DAT TIRF images were analyzed together to determine the fraction of DAT fluorescence that was associated with CTX-positive fluorescence. DAT and CTX 3-D image stacks were imported into FiJi (ImageJ), the best DAT focal plane was determined, and both DAT and CTX planes were extracted from that stack. If there was more than one expressing cell in the DAT image, the DAT and CTX image pairs were cropped to produce separate image pairs for each cell. Next, the DAT image was used to segment cell from background by first smoothing to reduce noise, then applying a visually determined, global intensity threshold, and creating a binary version of the DAT image. The original DAT and CTX images were multiplied by the binary DAT image to eliminate background from the analysis. Finally, the average DAT and CTX dark current intensities for the corresponding images were subtracted from the remaining pixels. Next, CTX images were analyzed to identify CTX-positive pixels using custom software. Contrast-to-noise CTX signals were not always sufficient to apply simple global intensity thresholds, thus we developed an approach to calculate for each pixel a likelihood (ranging from 0 to 1 ) that a pixel was CTX-positive. We modeled the gray level (intensity) histogram, GLH(i), of the CTX image as a simple linear sum of the CTX-negative $(\mathrm{ctx}-)$ and CTX-positive $(\mathrm{ctx}+)$ histograms:

$$
G L H(i)=G L H_{\mathrm{ctx}-}(i)+G L H_{\mathrm{ctx}+}(i)
$$

where the distribution of each species is a Gaussian:

$$
G L H_{\mathrm{ctx}-}(i)=A_{\mathrm{ctx}-} \cdot \exp \left(\frac{-\left(i-i_{\mathrm{ctx}-}\right)^{2}}{2 \cdot k \cdot \sigma^{2}}\right) ; k=1,
$$

and

$$
G L H_{\mathrm{ctx}+}(i)=A_{\mathrm{ctx}+}
$$

$$
\cdot \exp \left(\frac{-\left(i-\bar{i}_{\mathrm{ctx}+}\right)^{2}}{2 \cdot k \sigma^{2}}\right) ; k=\frac{\bar{i}_{\mathrm{ctx}+}}{\bar{i}_{\mathrm{ctx}-}}
$$

$A, \quad \bar{i}, \quad$ and $k \quad \cdot \sigma \quad{ }^{2}$ are the amplitude, mean $\left(\bar{i}_{\mathrm{ctx}-} \leq \bar{i}_{\mathrm{ctx}+}\right)$ and variance of each distribution, with the variance proportional to the mean. The GLH of the CTX image was calculated and fit with $\quad$ Equation using the Levenberg-Marquardt nonlinear curve-fitting algorithm of the Grace plotting package (http://plasma-gate.weizmann.ac.il/Grace/). The equation fit the GLH well in all cases, with $r^{2}=0.959 \pm 0.0031$ (mean \pm SEM, $n=123$ cells). The probability $P$ of a pixel of intensity $i$ being CTXpositive was calculated as follows:

$$
P_{\mathrm{ctx}+}(i)=\frac{G L H_{\mathrm{ctx}+}(i)}{G L H_{\mathrm{ctx}-}(i)+G L H_{\mathrm{ctx}+}(i)},
$$

for all cell (nonbackground) pixels. The percentage of DAT associated with CTX-positive pixels was calculated as follows:

$$
D A T_{\mathrm{ctx}+}=100 \frac{\sum^{x} \sum^{y}\left[D A T(x, y) \cdot P_{\mathrm{ctx}+}(C T X(x, y))\right]}{\sum^{x} \sum^{y} \operatorname{DAT}(x, y)},
$$

B
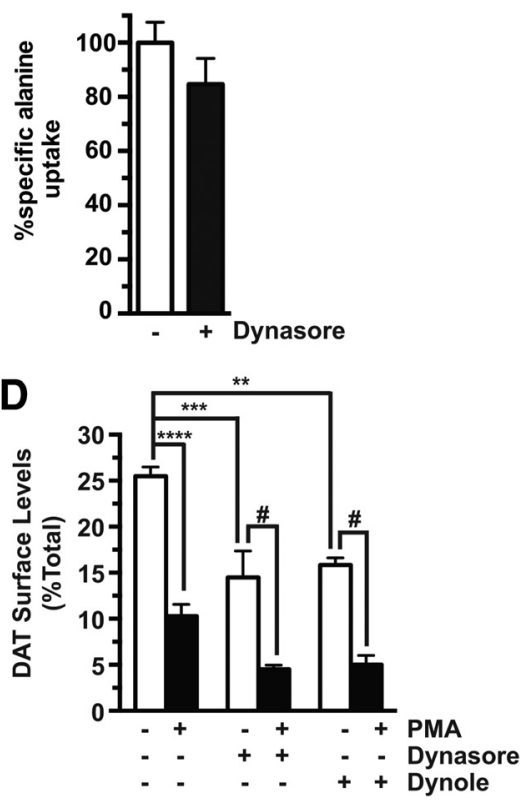

Figure 1. Dynamin inhibitors reduce DAT activity and surface levels, but do not inhibit PKC-stimulated DAT downregulation in PC12

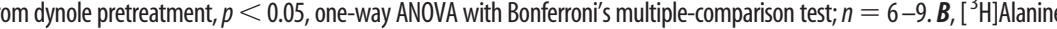
significantly different from vehicle-treated cells, ${ }^{* *} p<0.01,{ }^{* * *} p<0.001,{ }^{* * * *} p<0.0001$; \# indicates significantly different from pretreatment control, $p<0.05$, one-way ANOVA with Bonferroni's multiple-comparison test; $n=3-4$.

where $\operatorname{DAT}(x, y)$ and $\operatorname{CTX}(x, y)$ are the DAT and CTX fluorescence intensities at pixel $(x, y)$. The percentage $D A T_{\mathrm{ctx}}+$ was determined for each cell analyzed and the mean \pm SEM of all cells calculated.

Internalization assay. Relative DAT initial internalization rates were measured in DAT-SK-N-MC cells by reversible biotinylation as previously described (Loder and Melikian, 2003; Holton et al., 2005; Boudanova et al., 2008b). Cells plated in 6-well plates were pretreated \pm the indicated drugs, $20 \mathrm{~min}, 37^{\circ} \mathrm{C}$ and were rapidly chilled by washing three times with $\mathrm{PBS}^{2+}$. Surface proteins were biotinylated twice for $15 \mathrm{~min}, 4^{\circ} \mathrm{C}$ with $2.5 \mathrm{mg} / \mathrm{ml}$ NHS-SS-biotin and were quenched twice, $15 \mathrm{~min}, 4^{\circ} \mathrm{C}$ with $\mathrm{PBS}^{2+} / 100 \mathrm{~mm}$ glycine. One set of cells were kept at $4^{\circ} \mathrm{C}$ and were used to determine DAT surface levels at $\mathrm{t}=0$ and stripping efficiency. Cells were rapidly warmed to $37^{\circ} \mathrm{C}$ by washing three times in prewarmed $\mathrm{PBS}^{2+} / \mathrm{g} / \mathrm{BSA}$ containing the indicated drugs and incubated in the same solutions for $10 \mathrm{~min}, 37^{\circ} \mathrm{C}$, followed by rapidly cooling to $4^{\circ} \mathrm{C}$ to stop internalization. Residual surface biotin on internalization samples and stripping controls (cells that remained at $4^{\circ} \mathrm{C}$ ) was removed by reducing twice for $15 \mathrm{~min}, 4^{\circ} \mathrm{C}$ with $100 \mathrm{mM}$ Tris(2-carboxyethyl)phosphine (TCEP). Cells were lysed and biotinylated proteins were isolated with streptavidin agarose and analyzed by SDS-PAGE and immunoblotting for DAT as described above for steady state biotinylation. Internalization rates were calculated as the \% DAT internalized over 10 minutes as compared to total surface protein labeled at time $=0$. Assays were only included if stripping efficiencies were $>90 \%$. 
A
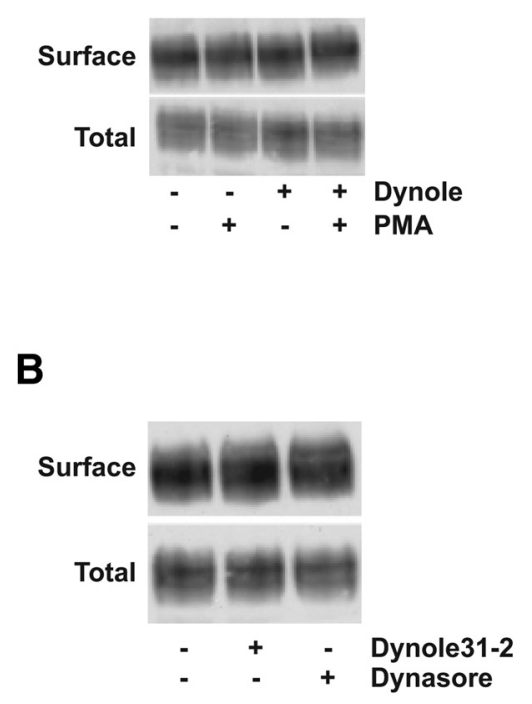
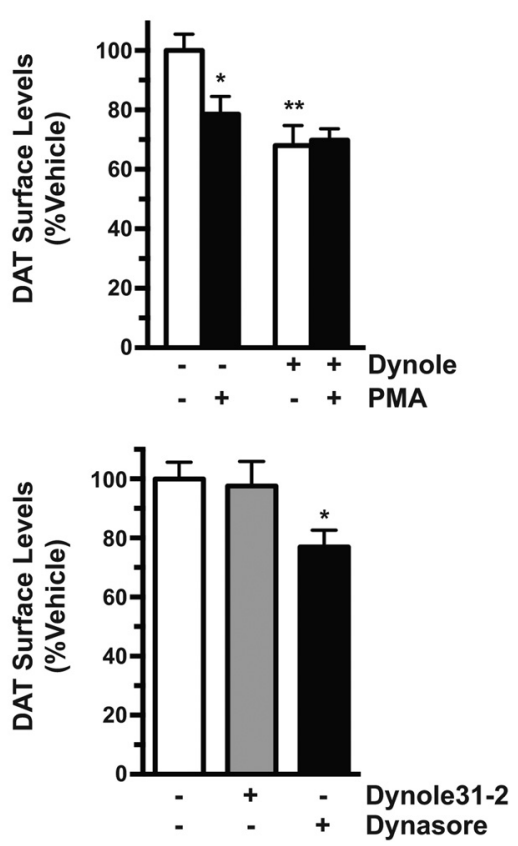

Figure 2. Dynamin inhibitors reduce DAT surface levels and inhibit PKC-stimulated DAT surface loss in SK-N-MC cells. Surface biotinylation studies. DAT-SK-N-MC cells were pretreated with or without the indicated dynamin inhibitors (or inactive analog, dynole $31-2$ ), $30 \mathrm{~min}, 37^{\circ} \mathrm{C}$, followed by treatment $\pm 1 \mu \mathrm{M}$ PMA, $30 \mathrm{~min}, 37^{\circ} \mathrm{C}$. Surface proteins were biotinylated and biotinylated proteins were isolated as described in Materials and Methods. A, Dynamin inhibition with dynole 34-1. Left, Representative DAT immunoblot showing surface and 1/3 total DAT. Right, Average data expressed as percentage vehicle DAT surface levels \pm SEM. Asterisks indicate significantly different from vehicle control, one-way ANOVA with Bonferroni's multiple-comparison test, ${ }^{*} p<$ $0.05,{ }^{* *} p<0.01 ; n=8$. $\boldsymbol{B}$. Dynamin inhibition with dynasore $(80 \mu \mathrm{m})$ or the inactive dynole analog $31-2(10 \mu \mathrm{m})$. Left, Representative DAT immunoblot showing surface and 1/3 total DAT. Right, Average data expressed as percentage vehicle DAT surface levels \pm SEM. *Significantly different from vehicle control, one-way ANOVA with Dunnett's multiple-comparison test, $p<$ $0.05 ; n=8$.

\section{Results}

If dynamin is required for basal DAT internalization we would expect that acutely inhibiting dynamin would either increase DAT function and surface levels, by blocking endocytosis and continuing to insert DAT into the plasma membrane, or would have no net effect on DAT surface levels by blocking both DAT endocytosis and recycling. Likewise, if dynamin were required for PKC-stimulated DAT internalization we would expect dynamin inhibition to attenuate PKC-stimulated DAT downregulation and surface loss. We first blocked dynamin function with dynasore, a noncompetitive dynamin GTPase inhibitor (Macia et al., 2006; Kirchhausen et al., 2008), and tested its effects on $\left[{ }^{3} \mathrm{H}\right]$ DA uptake in DAT-PC12 cells. PKC activation with $1 \mu \mathrm{M}$ PMA, $30 \mathrm{~min}, 37^{\circ} \mathrm{C}$ significantly decreased DA uptake to $33.2 \pm 3.2 \%$ control levels. Surprisingly, $80 \mu \mathrm{M}$ dynasore treatment, $30 \mathrm{~min}, 37^{\circ} \mathrm{C}$ significantly decreased DAT activity to $62.7 \pm 7.7 \%$ control levels (Fig. $1 ; n=9$ ). Following pretreatment with $80 \mu \mathrm{M}$ dynasore, $30 \mathrm{~min}, 37^{\circ} \mathrm{C} \mathrm{PKC}$ activation further decreased DA uptake to $23.0 \pm 3.5 \%$ vehicle levels, which was significantly less than dynasore treatment alone $(p<$ 0.05; Fig. 1A). Dynasore effects on DA uptake were not due to global perturbations in the transmembrane sodium gradient, as $\mathrm{Na}^{+}$dependent alanine transport was not significantly reduced by dynasore treatment $(p=0.33$; Fig. $1 B)$.

Dynasore-mediated DAT functional loss could be due to direct effects on transporter function or DAT depletion from the plasma membrane. To distinguish between these two possibilities we used surface biotinylation to measure DAT surface levels following dynasore treatment. Treatment with $80 \mu \mathrm{M}$ dynasore, 30

$\min , 37^{\circ} \mathrm{C}$ significantly reduced DAT surface levels to $55.9 \pm 9.2 \%$ control levels (Fig. 1C), demonstrating that DAT functional loss following dynasore treatment was due to DAT surface depletion. Treatment with $1 \mu \mathrm{M}$ PMA, $30 \mathrm{~min}, 37^{\circ} \mathrm{C}$ decreased DAT surface levels to $40.2 \pm 4.2 \%$ control levels, and dynasore pretreatment did not significantly inhibit further PMAstimulated DAT surface loss (Fig. 1C), suggesting that PKC-stimulated DAT internalization is dynamin-independent in PC12 cells. We further tested whether a chemically unrelated dynamin inhibitor, dynole 34-2, would similarly affect DAT surface levels. Dynole is an uncompetitive dynamin inhibitor with higher potency than dynasore (Hill et al., 2009). In control experiments, $10 \mu \mathrm{M}$ dynole completely blocked TfR endocytosis in control loading experiments using TfAlexa594 (data not shown). Pretreatment with $10 \mu \mathrm{M}$ dynole, $30 \mathrm{~min}, 37^{\circ} \mathrm{C}$ significantly decreased DAT surface levels to $62.7 \pm 5.5 \%$ control levels (Fig. 1C), and similar to dynasore, did not significantly inhibit further PMA-stimulated DAT surface loss. These results suggest that, in PC12 cells, both constitutive and PKC-stimulated DAT internalization are dynamin-independent. Moreover, constitutive DAT surface loss during dynamin inhibition strongly suggests that DAT endocytic recycling requires dynamin.

To test whether DAT surface loss in response to dynamin inhibition was dependent on cellular context, we also tested the effect of dynamin inhibitors on DAT stably expressed in the dopaminergic neuroblastoma cell line SK-N-MC (DAT-SK-N-MC cells). Similar to results observed in DAT-PC12 cells, $10 \mu \mathrm{M}$ dynole treatment, $30 \mathrm{~min}, 37^{\circ} \mathrm{C}$ significantly decreased DAT surface levels to $68.0 \pm 6.8 \%$ control levels, whereas the inactive analog, dynole $31-2$, had no significant effect on DAT surface levels (97.6 $\pm 8.4 \%$ control; Fig. $2 A)$. We next tested whether DAT undergoes PKC-mediated surface loss following dynole pretreatment. DAT-SK-N-MC cells were pretreated \pm 10 $\mu \mathrm{M}$ dynole, $30 \mathrm{~min}, 37^{\circ} \mathrm{C}$ followed by $\mathrm{PKC}$ activation with $1 \mu \mathrm{M}$ $\mathrm{PMA}, 30 \mathrm{~min}, 37^{\circ} \mathrm{C}$. Following vehicle pretreatment, PKC activation significantly decreased DAT surface levels to $78.6 \pm 6.0 \%$ control levels (Fig. 2A). In contrast, we observed no additional DAT surface loss in response to PKC activation following pretreatment with $10 \mu \mathrm{M}$ dynole, $30 \mathrm{~min}, 37^{\circ} \mathrm{C}$ (Fig. $2 \mathrm{~A}$ ). Moreover, total DAT levels were not significantly changed over the experimental time course following either dynole (119.6 $\pm 7.9 \%$ control levels) or PMA (115.4 $\pm 13.6 \%$ control levels) treatments (data not shown). To assure that dynole effects on DAT surface levels were not due to off-target effects, we also tested whether dynamin inhibition with dynasore affected DAT surface levels. Similar to our results with dynole, $80 \mu \mathrm{M}$ dynasore treatment, $30 \mathrm{~min}, 37^{\circ} \mathrm{C}$ significantly decreased surface DAT to $77.0 \pm 5.6 \%$ control levels (Fig. 2B).

Together with our PC12 cell data, our results suggested that constitutive DAT endocytosis is dynamin-independent and that dynamin inhibition either accelerates DAT endocytosis or blocks endocytic recycling, resulting in net DAT surface depletion. 
However, PKC-stimulated DAT surface loss was unaffected by dynamin inhibition in PC12 cells, whereas it was completely blocked in SK-N-MC cells. This prompted us to ask whether dynamin inhibitors similarly affected DAT surface levels in native dopaminergic neurons. To address this question, we performed ex vivo surface biotinylation studies in acute mouse striatal slices to test the effect of dynamin inhibition on DAT surface stability and PKC-stimulated internalization in intact adult dopaminergic terminals. In slices pretreated with vehicle, PKC activation with $1 \mu \mathrm{M}$ PMA, $30 \mathrm{~min}, 37^{\circ} \mathrm{C}$ significantly decreased DAT surface levels to $77.3 \pm 3.6 \%$ control levels (Fig. 3A). Treatment with $10 \mu \mathrm{M}$ dynole, $30 \mathrm{~min}$, $37^{\circ} \mathrm{C}$ likewise significantly decreased DAT surface levels to $80.7 \pm 4.6 \%$ control levels, and dynole pretreatment completely abolished further PKC-stimulated DAT surface loss. To assure that the biotinylation reagent did not permeate dopamine neurons, immunoblots were probed in parallel for tyrosine hydroxylase. Cellular integrity was not compromised during this protocol, as we routinely observed $<1 \%$ tyrosine hydroxylase biotinylation (Fig. 3B). Total DAT protein levels were unaffected by dynole or PMA treatments (PMA: $100.4 \pm 4.3 \%$ control levels; dynole: $104.4 \pm 5.3 \%$ control levels, $n=12$ ), suggesting that internalized DAT is not targeted to degradation in adult dopaminergic terminals. These results are consistent with those obtained in SK-N-MC cells, further supporting that dopaminergic SK-N-MC cells closely reflect neuronal DAT trafficking mechanisms.

Dynamin inhibition in SK-N-MC cells and striatal slices depleted surface DAT, suggesting that dynamin is not required for basal DAT internalization, and is likely required for DAT recycling back to the cell surface. Further, we observed no additional DAT surface loss in response to PKC activation following pretreatment with dynamin inhibitors. There are two possible interpretations of this result: (1) that PKC-stimulated DAT internalization is dynamin-dependent, or (2) that there is a finite DAT surface pool in SK-N-MC cells and adult dopaminergic neurons that is endocytic-willing, and that dynole treatment depleted this DAT pool from the cell surface. Thus, the remaining DAT surface pool would be endocytic-resistant and therefore unable to internalize following PKC activation, regardless of whether or not dynamin was required. If this were the case, our ability to test dynamin dependence under these experimental conditions would be limited. To distinguish between these two mechanistic possibilities, we used two independent approaches to blocking endocytic recycling and deplete the putative "endocytic-willing" DAT surface population in DAT-SK-N-MC cells: (1) monensin treatment, which blocks the vacuolar $\mathrm{H}^{+}$ATPase and has been shown to reduce DAT surface levels (Sorkina et al., 2009), and (2) $18^{\circ} \mathrm{C}$ temperature blockade, which was previously demonstrated to block DAT endocytic recycling (Loder and Melikian, 2003; Sorkina et al., 2009). We reasoned that if all surface DAT were endocytic-willing, we would observe continual DAT surface loss
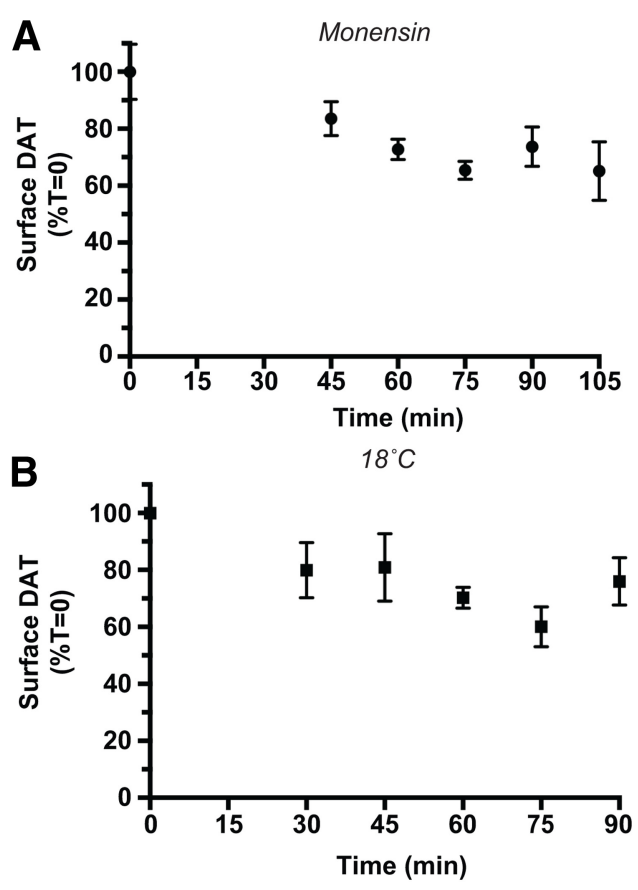

Figure 4. DAT surface loss plateaus over time during recycling blockade. Cell surface biotinylation studies; DAT-SK-N-MC cells were either treated with $10 \mu \mathrm{m}$ monensin, $37^{\circ} \mathrm{C}$ $(\boldsymbol{A})$ or incubated at $18^{\circ} \mathrm{C}(\boldsymbol{B})$ for the indicated times and surface DAT levels were measured by biotinylation as described in Materials and Methods. Average data are presented as percentage DAT surface levels at $t=0, n=4-6$. 

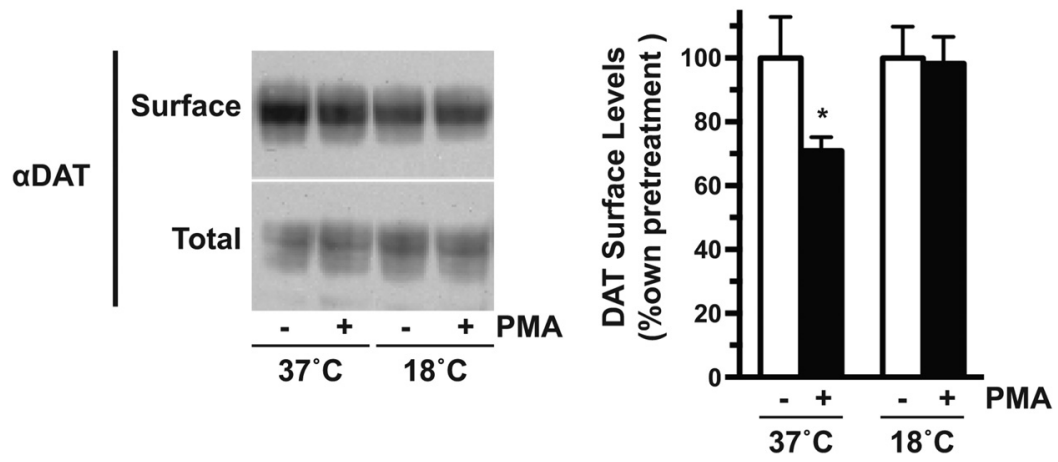

Figure 5. Recycling blockade reveals a DAT surface pool resistant to PKC-stimulated endocytosis. Cell surface biotinylation studies; DAT-SK-N-MC cells were preincubated for 45 min at either $37^{\circ} \mathrm{C}$ or $18^{\circ} \mathrm{C}$, followed by treatment with $1 \mu \mathrm{M}$ PMA, $30 \mathrm{~min}$, $37^{\circ} \mathrm{C}$ or $18^{\circ} \mathrm{C}$, respectively. DAT levels were subsequently measured by biotinylation as described in Materials and Methods. Left, Representative DAT immunoblot showing surface and $1 / 3$ total DAT in lysate after treatment with the indicated conditions. Right, Averaged data expressed as percentage pretreatment condition. *Significantly less than control, Student's $t$ test; $p<0.03, n=$ 6-12.

over time, whereas if there were an endocytic-resistant pool we would expect an initial surface loss that plateaus over time. Treatment with $25 \mu \mathrm{M}$ monensin, $37^{\circ} \mathrm{C}$ resulted in a gradual DAT surface depletion that plateaued by $60 \mathrm{~min}$ (Fig. $4 A$ ). Likewise, an $18^{\circ} \mathrm{C}$ recycling blockade resulted in gradual decreases in surface DAT that plateaued after $30 \mathrm{~min}$ (Fig. 4B). Together, these data are consistent with the hypothesis that DAT distributes into, at minimum, two distinct surface pools: one that is endocyticwilling and another that is endocytic-resistant for constitutive internalization. Interestingly, we only observed a trafficking resistant DAT pool in striatal slices and SK-N-MC cells, but not in PC12 cells (Fig. 1), suggesting that cellular context may strongly influence DAT's endocytic capacity and that SK-N-MC cells more closely reflect native DAT trafficking potential.

We next asked whether the remaining DAT surface pool, that was endocytic-resistant to constitutive internalization, was capable of PKC-stimulated internalization. DAT-SK-N-MC cells were preincubated at $18^{\circ} \mathrm{C}$ to deplete the endocytic-willing DAT surface population, followed by PKC activation with $1 \mu \mathrm{M}$ PMA, $45 \mathrm{~min}, 18^{\circ} \mathrm{C}$. In cells preincubated at $37^{\circ} \mathrm{C}$, PKC activation reduced DAT surface levels to $70.9 \pm 4.3 \%$ vehicle levels (Fig. 5 ). In contrast, when the endocytic-willing DAT surface pool was depleted at $18^{\circ} \mathrm{C}, 45 \mathrm{~min}$ we observed no further DAT surface loss in response to PKC activation $(98.3 \pm 9.4 \%$ control levels, $p=0.45$, $n=8-15$ ), consistent with a trafficking-resistant DAT surface population. The lack of PKC-stimulated DAT surface loss at $18^{\circ} \mathrm{C}$ was not due to inability of PMA to activate PKC at $18^{\circ} \mathrm{C}$, as PMA treatment at $18^{\circ} \mathrm{C}$ was capable of significantly decreases DAT surface expression in PC12 cells (data not shown), which do not express a endocytic-resistant DAT surface pool. Thus, the inability of DAT to internalize in response to $\mathrm{PKC}$ activation following an $18^{\circ} \mathrm{C}$ surface depletion that we observed in SK-N-MC cells was likely due to a loss of the endocytic-willing DAT surface pool.

We next tested whether the endocytic-resistant DAT surface pool was present in adult dopaminergic neurons by asking (1) whether monensin would deplete surface DAT in acute mouse striatal slices and (2) whether the residual DAT surface pool was responsive to PKC activation. The results are shown in Figure 6. Identical to our results in DAT-SK-N-MC cells, monensin pretreatment significantly decreased DAT surface levels to $72.0 \pm$ $5.7 \%$ vehicle-pretreated cells ( $p<0.004$, Student's $t$ test, $n=21$ ). $\mathrm{PKC}$ activation significantly reduced DAT surface levels to $73.3 \pm$ 3.3 percent vehicle levels, and monensin pretreatment completely blocked further PKC-stimulated reduction in DAT surface expression (Student's $t$ test, $p=0.40)$, consistent with the presence of an endocytic-resistant DAT surface pool in adult striatal dopaminergic neurons. Neither monensin nor PMA treatments decreased total DAT protein levels (data not shown). We did note, however, that monensin slightly increased cell permeability to the biotinylation reagent, permitting $\sim 8 \%$ of $\mathrm{TH}$ to be biotinylated in the monensintreated slices (Fig. 6B). Together with our results in SK-N-MC cells, these results suggest that DAT is distributed between endocytic-willing and -resistant surface pools.

We next investigated the possible physical basis for the endocytic-willing and -resistant DAT surface pools. Previous studies reported that DAT partitions between lipid raft and nonraft plasma membrane microdomains (Adkins et al., 2007; Foster et al., 2008; Cremona et al., 2011; Navaroli et al., 2011), and that flotillin-1 retains DAT in lipid rafts (Cremona et al., 2011; Sorkina et al., 2013) and is required for PKC-stimulated DAT endocytosis (Cremona et al., 2011) in HEK cells. Thus, we asked whether the endocytic-willing DAT surface pool preferentially arises from either raft or nonraft loci in SKN-MC cells. To address this possibility, we used TIRF microscopy to quantify TagRFP-T-DAT surface colocalization with Alexa488-CTX following treatment $\pm 10 \mu \mathrm{M}$ dynole, $30 \mathrm{~min}$, $37^{\circ} \mathrm{C}$. TagRFP is a monomeric RFP that is $\sim 3$-fold brighter than mCherry (Shaner et al., 2004), and control experiments confirmed that TagRFP-T-DAT expresses, functions and is subject to PKC-mediated downregulation comparable to wild-type DAT (data not shown). If the endocytic-willing DAT pool preferentially internalizes from either membrane rafts or nonrafts, we would expect to detect either a decrease or increase in the percentage surface TagRFP-T-DAT localized to CTX-positive pixels, respectively. Alternatively, if DAT internalizes equivalently from rafts and nonrafts, we would expect no shift in the overall percentage surface TagRFP-T-DAT localized to CTX-positive pixels. The ensemble dataset is shown in Figure 7. In vehicle-treated cells, $67.7 \pm 2.4 \%$ surface TagRFP-T-DAT colocalized in CTXpositive pixels. Following treatment with $10 \mu \mathrm{M}$ dynole, $30 \mathrm{~min}$, $37^{\circ} \mathrm{C}$, TagRFP-T-DAT distribution in CTX-positive pixels was not significantly different from vehicle-treated cells $(65.6 \pm 2.2 \%$ surface DAT), suggesting that the endocytic-willing population internalized equivalently from membrane raft and nonraft microdomains. To assure that preferential raft internalization was detectable in our system, we also measured the TagRFP-T-DAT surface distribution following PKC activation with $1 \mu \mathrm{M}$ PMA, 30 $\min , 37^{\circ} \mathrm{C}$. Following PKC activation TagRFP-T-DAT colocalization in CTX-positive pixels significantly decreased to $58.5 \pm$ $3.6 \%$ surface DAT ( $p<0.05$, one-way ANOVA with Dunnett's multiple-comparison test). These data suggest that raft-specific loss is detectable in our system and are consistent with previous results demonstrating that PKC-stimulated decreases in DAT surface expression occur primarily from membrane raft microdomains (Cremona et al., 2011).

Dynamin inhibition for $60 \mathrm{~min}$ completely depleted the endocytic-willing DAT surface pool in both striatal slices and SK-N-MC cells. Therefore, it was not possible to interpret whether lack of PKC-stimulated DAT internalization following 
dynole treatment was due actual dynamin dependence, or an a priori inability of the remaining DAT surface population to internalize regardless of whether or not dynamin was active. Moreover, dynole/ dynasore-mediated DAT surface depletion could be due to enhanced internalization or reduced endocytic recycling. To directly test whether dynamin was required for constitutive and PKC-stimulated DAT endocytosis, we used reverse biotinylation to measure the effect of dynole on basal and PKC-stimulated DAT internalization rates in SK-N-MC cells. The advantage of this approach is that we can measure DAT internalization rates directly, before depleting the endocyticwilling DAT surface pool. For these experiments, we pretreated cells $\pm 10 \mu \mathrm{M}$ dynole for $20 \mathrm{~min}, 37^{\circ} \mathrm{C}$, before biotinylation. This pretreatment did not completely deplete the endocytic-willing DAT surface pool, as determined in a dynole time course, but allowed sufficient time for dynole to inhibit dynamin, as determined in Tf loading assays (data not shown). Following vehicle pretreatment, DAT robustly internalized and PKC activation significantly increased DAT internalization rates to $179 \pm 20.5 \%$ control levels (Fig. 8). Dynole preincubation did not significantly inhibit constitutive DAT internalization rates. However, dynole completely blocked PKC-enhanced DAT internalization rates (Fig. 8). Thus, DAT surface loss in response to dynamin inhibition is not due to accelerated constitutive DAT endocytosis, and is likely caused by blocked endocytic recycling back to the plasma membrane. Moreover, these results demonstrate that regulated DAT endocytosis is differentially dependent upon dynamin: constitutive DAT internalization is dynamin-independent, whereas PKC-stimulated DAT internalization is dynamin-dependent.

Mounting evidence indicates that, in addition to its obligate role in clathrin-mediated endocytosis, dynamin directly interacts with the actin cytoskeleton and is required for cortical actin cytoskeleton dynamics. Moreover, actin/dynamin interactions are reported to play a central role in recycling via the bulk endocytic route. We postulated that dynamin might be required for DAT endocytic recycling via its interactions with the actin cytoskeleton. To test this possibility, we used cytochalasin $\mathrm{D}$ (CytoD) to disrupt the actin filaments in striatal slices and tested whether actin was also required for dynamin-dependent DAT surface stability. Slices were pretreated with either vehicle or $0.2 \mu \mathrm{g} / \mathrm{ml} \mathrm{CytoD,} 30 \mathrm{~min}, 37^{\circ} \mathrm{C}$, followed by treatment either with vehicle or $10 \mu \mathrm{M}$ dynole, $30 \mathrm{~min}$, $37^{\circ} \mathrm{C}$. The results are shown in Figure 9. CytoD treatment alone significantly reduced DAT surface levels to $69.9 \pm 5.1 \%$ control levels. Dynole treatment significantly reduced DAT surface levels to $67.2 \pm 5.0 \%$ control levels and CytoD pretreatment completely blocked further dynole-mediated DAT surface loss. CytoD had no effect on slice permeability to the biotinylation reagent, as determined in immunoblots probed for TH in parallel (data not shown). CytoD treatment did not target DAT to a degradative fate, as total DAT protein levels were unchanged over the course of the experiment (91.7 $\pm 10.1 \%$ control levels). Moreover, CytoD did not glob-
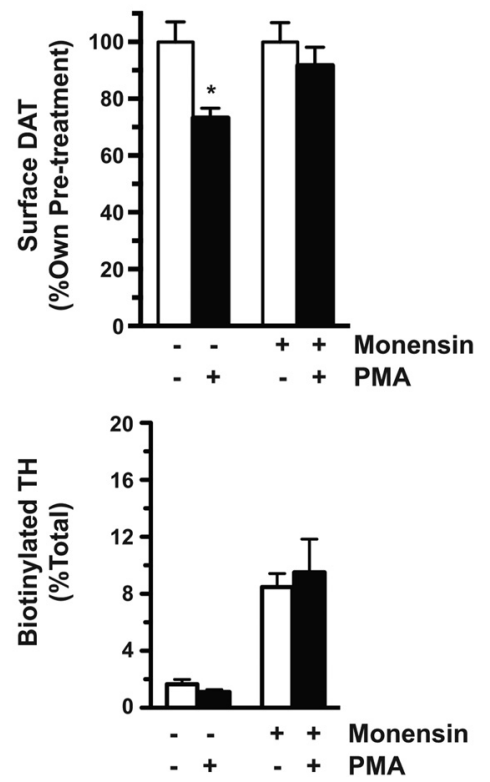

Figure 6. Recycling blockade reveals an endocytic-resistant DAT surface population in adult dopaminergic neurons. Ex vivo striatal slice biotinylation studies. Coronal slices were prepared from mouse striatum as described in Materials and Methods. Slices were pretreated $\pm 25 \mu \mathrm{m}$ monensin, $60 \mathrm{~min}, 37^{\circ} \mathrm{C}$ and were subsequently treated $\pm 1 \mu \mathrm{MPMA}, 30 \mathrm{~min}, 37^{\circ} \mathrm{C}$. Surface proteins Representative TH immunoblots showing biotinylated and total TH in equivalent amounts of tissue lysate. Right, Average data percentage total TH biotinylated $\pm \mathrm{SEM} ; n=21$.

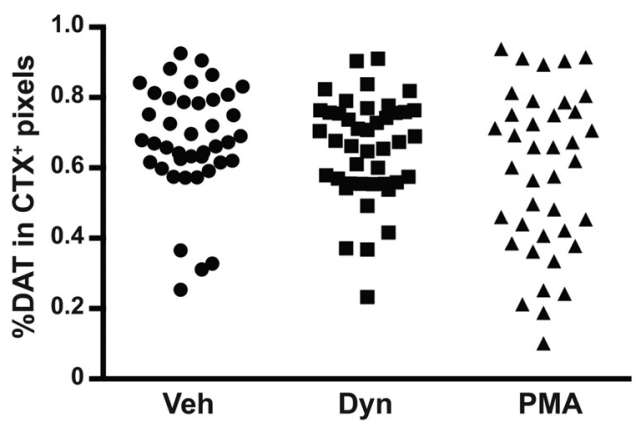

Figure 7. The endocytic-willing DAT surface population arises independent of membrane raft microdomains. TIRF microscopy studies; SK-N-MC cells stably expressing Tag-RFP-T-DAT were treated $\pm 10 \mu \mathrm{m}$ dynole or $1 \mu \mathrm{m}$ PMA, $30 \mathrm{~min}, 37^{\circ} \mathrm{C}$, were labeled with Alexa488 CTX-B, $4^{\circ} \mathrm{C}$, fixed, and surface signals were imaged via TIRF microscopy as described in Materials and Methods. The percentage total surface DAT localized to CTX-positive was determined as described. Graph depicts DAT/CTX colocalization for all cells imaged ( $n=40$, vehicle; 42 , dynole; 38, PMA).

ally disrupt endocytic trafficking, as TfR surface levels were not significantly altered by CytoD treatment $(118 \pm 12.6 \%$ control; Fig. $9 B)$. Together, with our dynamin results, these data suggest that dynamin activity controls DAT endocytic recycling in a manner that engages with the actin cytoskeleton, but that constitutive DAT internalization is both dynamin- and actin-independent.

\section{Discussion}

Previous studies using siRNA or dominant-negative mutants report that constitutive, PKC-stimulated and AMPH-stimulated DAT internalization are dynamin-dependent (Daniels and Amara, 1999; Saunders et al., 2000; Sorkina et al., 2005; Eriksen et al., 2009). However, several lines of evidence support that nonclassical endocytic 

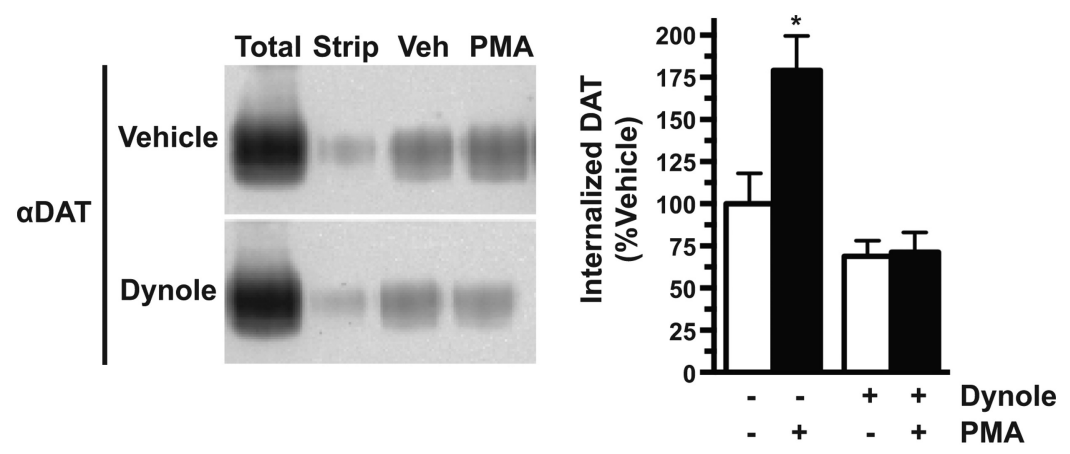

Figure 8. Constitutive DAT internalization is dynamin-independent, whereas PKC-stimulated DAT internalization is dynamindependent. DAT internalization assays; DAT-SK-N-MC cells were pretreated $\pm 10 \mu$ m dynole, $20 \mathrm{~min}, 37^{\circ} \mathrm{C}$, and DAT internalization rates were measured by reversible biotinylation $\pm 10 \mu \mathrm{m}$ dynole, $\pm 1 \mu \mathrm{MPMA}, 10 \mathrm{~min}, 37^{\circ} \mathrm{C}$ as described in Materials and Methods. Left, Representative DAT immunoblots. For each pretreatment condition (vehicle, top; $10 \mu \mathrm{m}$ dynole, bottom), blots show total surface DAT att $=0$ (total), strip control (strip), and amount of DAT internalized in the presence of vehicle or PMA. Right, Averaged data, expressed as percentage vehicle-treated cells \pm SEM. *Significantly different from vehicle, one-way ANOVA with Bonferroni's multiple-comparison test; $p<0.05, n=4$.

A
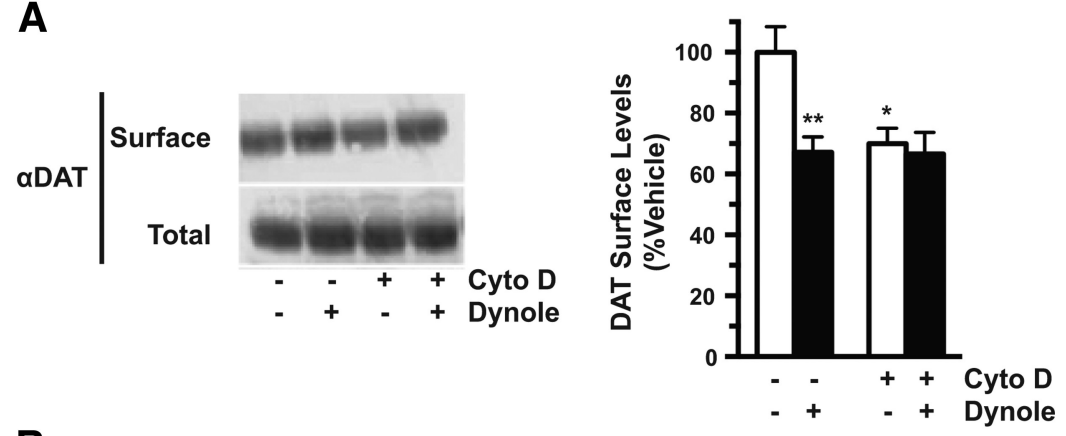

B
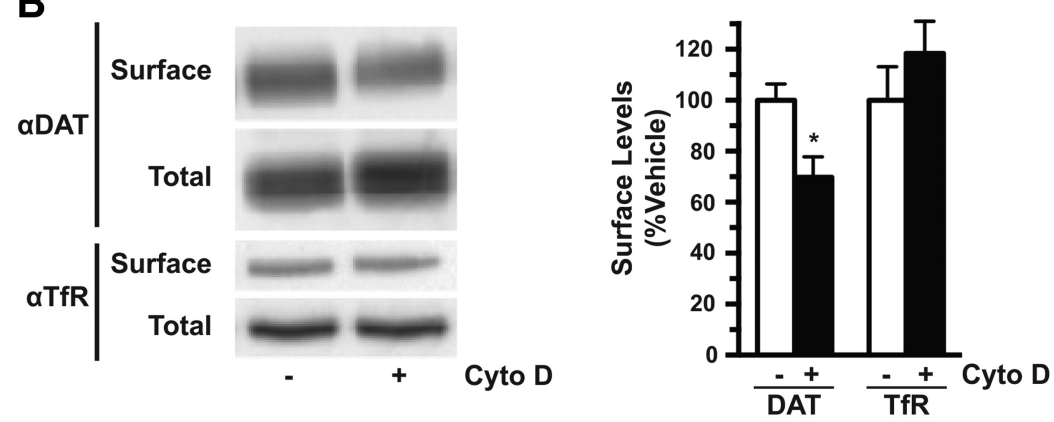

Figure 9. Dynamin mediates DAT recycling via an actin-dependent mechanism in adult dopaminergic neurons. Ex vivo striatal slice biotinylation studies. Coronal slices were prepared from mouse striatum as described in Materials and Methods. Slices were pretreated $\pm 0.2 \mu \mathrm{g} / \mathrm{ml}$ cytochalasin $\mathrm{D}, 30 \mathrm{~min}, 37^{\circ} \mathrm{C}$, and were subsequently treated $\pm 10 \mu \mathrm{m}$ dynole, $30 \mathrm{~min}, 37^{\circ} \mathrm{C}$. Surface proteins were biotinylated and isolated as described in Materials and Methods. A, DAT biotinylation. Left, Representative DAT immunoblots showing surface and total DAT in equivalent amounts of tissue lysate. Right, Average DAT surface levels expressed as percentage vehicle-treated DAT levels \pm SEM. Asterisks indicate significantly different from vehicle, one-way ANOVA with Bonferroni's multiple-comparison test; ${ }^{*} p<0.05,{ }^{* *} p<0.01, n=7$. B , Effect of CytoD on DAT and TfR surface levels. Left, Representative immunoblots showing biotinylated and total DAT (top) and TfR (bottom) in equivalent amounts of tissue lysate following treatment $\pm 0.2 \mu \mathrm{g} / \mathrm{ml}$ CytoD. Right, Average data expressed as percentage vehicle surface levels \pm SEM. ${ }^{*}$ Significantly different from vehicle control, Student's $t$ test; $p<0.02, n=6$.

mechanisms facilitate constitutive and PKC-stimulated DAT endocytosis. DAT relies on a noncanonical carboxy terminal endocytic signal (Miranda et al., 2004; Holton et al., 2005) and an endocytic brake tempers constitutive DAT internalization rates (Boudanova et al., 2008b; Sorkina et al., 2009). PKC-stimulated DAT internalization requires the neuronal GTPase, Rin (Navaroli et al., 2011), which has not previously been implicated in either clathrin- or dynamindependent endocytosis. Moreover, the lipid raft protein, flotillin-1, retains DAT in membrane raft microdomains and is required for
PKC-stimulated DAT internalization (Cremona et al., 2011). It should be noted that a recent study indicated that although flotillin-1 retains DAT in lipid microdomains, it is not required for PKC-stimulated DAT internalization (Sorkina et al., 2013). Why have such disparate mechanisms been observed for constitutive and PKC-stimulated DAT endocytosis? To date, DAT trafficking studies have been performed primarily in non-neuronal cell lines or cultured midbrain neurons derived from $\mathrm{P} 0-\mathrm{P} 2$ rodents, which may not faithfully recapitulate endocytic mechanisms inherent in adult dopaminergic neurons. Studies comparing DAT surface dynamics in HEK versus Neuro2A cells similarly found striking differences in DAT lateral mobility between the two cell types (Adkins et al., 2007). Indeed, our current results comparing PC12 cells, SK-N-MC cells and striatal slices clearly demonstrate that DAT's dynamin dependence is highly sensitive to cellular context (Figs. 1-3). Interestingly, SK-N-MC cellsidentically recapitulated striatal slice results, suggesting that SK-N-MC neuroblastoma is a reliable culture model for constitutive and PKC-stimulated DAT internalization studies. Interestingly, constitutive and PKC-stimulated DAT endocytic rates are markedly larger in PC12 cells (Loder and Melikian, 2003) than in either SK-N-MC cells or striatal slices (Figs. 2, $3,8)$. Because PC12 cells lack an endocyticresistant DAT surface pool, it is possible that mechanisms limiting DAT's endocytic capacity in SK-N-MC cells and striatal dopaminergic terminals may also dampen DAT endocytic rates. In addition to contextual differences, many studies used siRNA and dominant-negative expression approaches that chronically inhibit dynamin over days. Because dynamin is required for multiple membrane fission events, including exit from the trans-Golgi network, it is possible that dynamin-independent mechanisms were secondarily perturbed.

Numerous studies in cell lines determined that PKC enhances DAT internalization (Melikian and Buckley, 1999; Granas et al., 2003; Miranda et al., 2005, 2007; Boudanova et al., 2008b; Foster et al., 2008; Navaroli et al., 2011; Sakrikar et al., 2012; Sorkina et al., 2013). However, several investigations in cultured dopaminergic neurons indicate that $\mathrm{PKC}$ activation does not induce DAT sequestration (Sorkina et al., 2006; Eriksen et al., 2009; Rao et al., 2011, 2012), questioning the physiological relevance of PKC-stimulated DAT internalization. Consistent with a recent report (Cremona et al., 2011), we readily detected PKC-induced DAT sequestration in striatal slices (Fig. 3), demonstrating that native DAT internalizes in response to PKC activation in mature dopaminergic terminals. Unlike cultured cells, intact striatal slices retain multiple regional synaptic connections. Thus, because PKC was activated across the entire slice, it is possible that $\mathrm{PKC}$ activation 


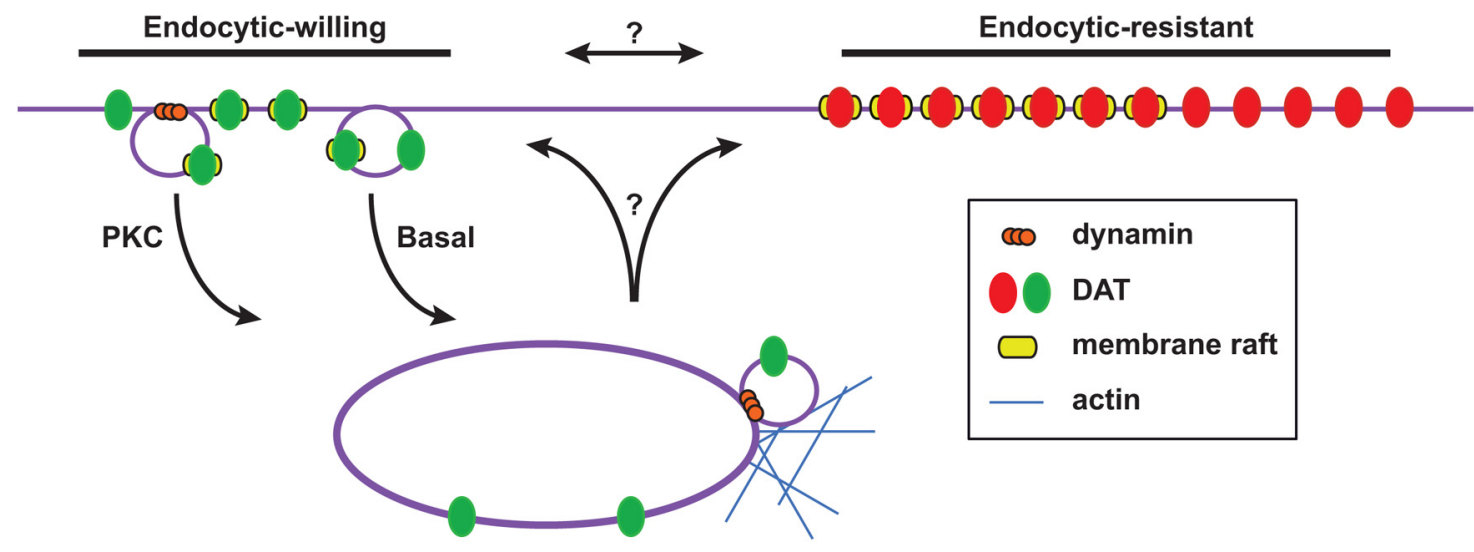

Figure 10. Model for constitutive and PKC-regulated DAT endocytic trafficking at dopaminergic terminals. Surface DAT distributes into endocytic-willing $(\sim 30 \%)$ and endocytic resistant $(\sim 70 \%)$ pools, and also into lipid raft and nonraft membrane microdomains. Both constitutive and PKC-stimulated DAT endocytosis arise from the endocytic willing surface pool but are differentially dependent upon dynamin: constitutive DAT internalization is dynamin-independent, whereas PKC-stimulated DAT internalization is dynamin-dependent. Membrane raft microdomains also play distinct roles in DAT internalization-constitutive DAT internalization occurs equivalently from raft and nonraft domains, whereas PKC-stimulated DAT endocytosis emanates exclusively from flotillin-rich lipid rafts microdomains. Once internalized, DAT endocytic recycling back to the plasma membrane critically relies upon dynamin working in concert with the actin cytoskeleton.

in afferents synapsing onto the dopaminergic terminals could have contributed to DAT surface loss. For example, Group I mGluRmediated PKC activation stimulates DAT-mediated DA release in substantia nigra slices (Opazo et al., 2010) that, in turn, could have driven DAT surface loss via well described substrate-mediated DAT internalization (Saunders et al., 2000; Zahniser and Sorkin, 2004; Boudanova et al., 2008a; Hong and Amara, 2013).

Studies investigating DAT's intracellular fate following internalization have yielded varying results. When bound to extracellular antibody or fluorescent ligand, constitutively internalized DAT targets to rab4 "short-loop" endosomes, late endosomes, and lysosomes (Eriksen et al., 2010). In contrast, biochemical studies examining unlabeled or biotinylated DAT demonstrate that DAT robustly recycles to the plasma membrane (Loder and Melikian, 2003; Boudanova et al., 2008a; Chen et al., 2013), targets to TfR- and rab11-positive recycling endosomes in neuronal cell lines and synaptosomes (Melikian and Buckley, 1999; Sorkina et al., 2003; Furman et al., 2009) and that rab11 activity regulates DAT surface expression (Furman et al., 2009). Moreover, striatal fractionation demonstrated that DAT is enriched in TfR-positive, but not late endosomal (rab7-positive), organelles, both under basal and PKC-activated conditions (Rao et al., 2011). Total DAT levels were unchanged in both SK-N-MC cells (Fig. 2) and striatal slices (Fig. 3) following 30 min PKC activation, suggesting that DAT does not degrade following internalization, consistent with our previous findings in PC12 cells (Loder and Melikian, 2003; Holton et al., 2005). Recent studies demonstrated that TfR, rabies $G$ glycoprotein, and $\beta$-amyloid anomalously target to degradation if internalized while bound to antibody (Tampellini et al., 2007; St Pierre et al., 2011), suggesting that antibody/DAT complexes may anomalously target to degradation. Additionally, given that PKC-stimulated DAT endocytic mechanisms are quite sensitive to cellular context (Figs. 1-3), it is possible that results from either non-neuronal cell lines or primary dopaminergic neurons may not reflect PKC-stimulated DAT internalization in adult neurons. Finally, reported DAT degradation occurs in instances where PKC is chronically activated (1-2 h), which may not reflect rapid kinase activation/inactivation inherent to normal neuronal signaling.

We observed that DAT's endocytic capacity functionally segregates into "endocytic willing" and "endocytic-resistant" surface pools in SK-N-MC cells and striatal slices (Figs. 5, 6). Moreover, both constitutive and PKC-stimulated DAT internalization emanate from the endocytic-willing pool. Although these pools are functionally evident, we currently do not know the physical basis for these DAT surface pools. Moreover, it is not clear whether AMPH-stimulated DAT internalization is also limited to this pool, but future studies should be interesting in this regard. The endocytic-resistant DAT pool could be absolutely fixed, and may have evolved to assure that dopaminergic terminals have a baseline minimal DA clearance capacity. Alternatively, there may be as yet unknown conditions that can recruit or limit DAT to and from the endocytic-willing pool. Studies from Sankaranarayanan and Ryan (2001) showed that intracellular calcium elevations enhance synaptic vesicle endocytic capacities (Balaji et al., 2008). Although synaptic vesicle endocytosis is markedly faster than DAT internalization, these results suggest that neuronal endocytic capacities are highly plastic and that DAT's absolute endocytic potential may be subject to change.

Previous fractionation studies indicated that DAT segregates into membrane raft and nonraft membrane microdomains (Adkins et al., 2007; Foster et al., 2008; Cremona et al., 2011). Our TIRF studies revealed that constitutive DAT internalization arises equivalently from raft and nonraft domains (Fig. 7), suggesting that DAT's absolute endocytic capacity is not dictated by lipid raft localization. Because our TIRF studies were performed in fixed cells using TagRFP-T-DAT, we cannot rule out the possibility that DAT internalized preferentially from one microdomain and was either replaced either by newly inserted DAT or via redistribution from another microdomain before fixation. Future studies specifically examining DAT surface dynamics in real time should shed further light on this possibility.

Although constitutive DAT internalization is dynaminindependent and microdomain nonselective, PKC-stimulated DAT endocytosis is dynamin-dependent (Fig. 8) and arises strictly from CTX-positive membrane rafts (Fig. 7). These results are consistent with previous studies in which flotillin-1-mediated DAT targeting to CTX-positive microdomains was required for PKC-stimulated DAT internalization (Cremona et al., 2011). Moreover, previous work from our laboratory demonstrated that Rin GTPase interactions with DAT are required for PKCstimulated DAT internalization, and are enriched in lipid raft microdomains (Navaroli et al., 2011). In contrast, fractionation studies performed in LLC-PK1 cells revealed that PKC- 
stimulated DAT surface loss arises strictly from nonraft membrane microdomains (Foster et al., 2008). These contrasting results may reflect detection of internalized raft microdomains by fractionation, whereas TIRF imaging examines plasma membrane directly. Alternatively, disparate findings may reflect inherent differences between neuronal and non-neuronal cellular backgrounds.

Our results demonstrate that constitutive DAT internalization is dynamin-independent (Figs. 2, 3, 8), and suggest that a dynamin- and actin-dependent mechanism controls DAT endocytic recycling (Fig. 9). Recent studies indicate that dynamin directly links to the actin cytoskeleton via cortactin interactions, and is required for Arp2/3 actin filament recruitment to maintain the cortical actin network (Schafer, 2004; Menon and Schafer, 2013). Moreover, receptors subject to sequence-dependent recycling, such as the $\beta 2$-adrenergic receptor, segregate to biochemically distinct endosomal microdomains and require actin and Arp2/3 for recycling (Puthenveedu et al., 2010). Thus, dynamin may be integral to DAT recycling via its direct interaction with the actin cytoskeleton.

Given our results, we propose a constitutive and PKCstimulated endocytic trafficking model for DAT, depicted in Figure 10. Currently, it is unclear whether recycling DAT inserts into endocytic-willing populations, or whether DAT can shift between endocytic-willing and -resistant pools postinsertion. Moreover, it is not known whether DAT recycling is mediated by sequence-dependent or bulk flow mechanisms. Future studies directly examining DAT surface dynamics and recycling determinants should reveal the multimodal mechanisms dictating basal and PKC-stimulated DAT endocytic trafficking.

\section{References}

Adkins EM, Samuvel DJ, Fog JU, Eriksen J, Jayanthi LD, Vaegter CB, Ramamoorthy S, Gether U (2007) Membrane mobility and microdomain association of the dopamine transporter studied with fluorescence correlation spectroscopy and fluorescence recovery after photobleaching. Biochemistry 46:10484-10497. CrossRef Medline

Amara SG, Sonders MS, Zahniser NR, Povlock SL, Daniels GM (1998) Molecular physiology and regulation of catecholamine transporters. Adv Pharmacol 42:164-168. Medline

Balaji J, Armbruster M, Ryan TA (2008) Calcium control of endocytic capacity at a CNS synapse. J Neurosci 28:6742-6749. CrossRef Medline

Boudanova E, Navaroli DM, Melikian HE (2008a) Amphetamine-induced decreases in dopamine transporter surface expression are protein kinase C-independent. Neuropharmacology 54:605-612. CrossRef Medline

Boudanova E, Navaroli DM, Stevens Z, Melikian HE (2008b) Dopamine transporter endocytic determinants: carboxy terminal residues critical for basal and PKC-stimulated internalization. Mol Cell Neurosci 39:211-217. CrossRef Medline

Bowton E, Saunders C, Erreger K, Sakrikar D, Matthies HJ, Sen N, Jessen T, Colbran RJ, Caron MG, Javitch JA, Blakely RD, Galli A (2010) Dysregulation of dopamine transporters via dopamine D2 autoreceptors triggers anomalous dopamine efflux associated with attention-deficit hyperactivity disorder. J Neurosci 30:6048-6057. CrossRef Medline

Bröer S, Gether U (2012) The solute carrier 6 family of transporters. Br J Pharmacol 167:256-278. CrossRef Medline

Chen R, Daining CP, Sun H, Fraser R, Stokes SL, Leitges M, Gnegy ME (2013) Protein kinase $C \beta$ is a modulator of the dopamine D2 autoreceptor-activated trafficking of the dopamine transporter. J Neurochem 125:663-672. CrossRef Medline

Cremona ML, Matthies HJ, Pau K, Bowton E, Speed N, Lute BJ, Anderson M, Sen N, Robertson SD, Vaughan RA, Rothman JE, Galli A, Javitch JA, Yamamoto A (2011) Flotillin-1 is essential for PKC-triggered endocytosis and membrane microdomain localization of DAT. Nat Neurosci 14: 469-477. CrossRef Medline

Daniels GM, Amara SG (1999) Regulated trafficking of the human dopamine transporter: clathrin-mediated internalization and lysosomal deg- radation in response to phorbol esters. J Biol Chem 274:35794-35801. CrossRef Medline

Eriksen J, Rasmussen SG, Rasmussen TN, Vaegter CB, Cha JH, Zou MF, Newman AH, Gether U (2009) Visualization of dopamine transporter trafficking in live neurons by use of fluorescent cocaine analogs. J Neurosci 29:6794-6808. CrossRef Medline

Eriksen J, Bjørn-Yoshimoto WE, Jørgensen TN, Newman AH, Gether U (2010) Postendocytic sorting of constitutively internalized dopamine transporter in cell lines and dopaminergic neurons. J Biol Chem 285: 27289-27301. CrossRef Medline

Foster JD, Adkins SD, Lever JR, Vaughan RA (2008) Phorbol ester induced trafficking-independent regulation and enhanced phosphorylation of the dopamine transporter associated with membrane rafts and cholesterol. J Neurochem 105:1683-1699. CrossRef Medline

Furman CA, Lo CB, Stokes S, Esteban JA, Gnegy ME (2009) Rab 11 regulates constitutive dopamine transporter trafficking and function in N2A neuroblastoma cells. Neurosci Lett 463:78-81. CrossRef Medline

Gether U, Andersen PH, Larsson OM, Schousboe A (2006) Neurotransmitter transporters: molecular function of important drug targets. Trends Pharmacol Sci 27:375-383. CrossRef Medline

Granas C, Ferrer J, Loland CJ, Javitch JA, Gether U (2003) N-terminal truncation of the dopamine transporter abolishes phorbol ester- and substance P receptor-stimulated phosphorylation without impairing transporter internalization. J Biol Chem 278:4990-5000. CrossRef Medline

Hamilton PJ, Campbell NG, Sharma S, Erreger K, Herborg Hansen F, Saunders C, Belovich AN, Sahai MA, Cook EH, Gether U, McHaourab HS, Matthies HJ, Sutcliffe JS, Galli A (2013) De novo mutation in the dopamine transporter gene associates dopamine dysfunction with autism spectrum disorder. Mol Psychiatry CrossRef Medline

Hill TA, Gordon CP, McGeachie AB, Venn-Brown B, Odell LR, Chau N, Quan A, Mariana A, Sakoff JA, Chircop M, Robinson PJ, McCluskey A (2009) Inhibition of dynamin mediated endocytosis by the dynolessynthesis and functional activity of a family of indoles. J Med Chem 52: 3762-3773. CrossRef Medline

Holton KL, Loder MK, Melikian HE (2005) Nonclassical, distinct endocytic signals dictate constitutive and PKC-regulated neurotransmitter transporter internalization. Nat Neurosci 8:881-888. CrossRef Medline

Hong WC, Amara SG (2013) Differential targeting of the dopamine transporter to recycling or degradative pathways during amphetamine- or PKC-regulated endocytosis in dopamine neurons. FASEB J 27:29953007. CrossRef Medline

Hyman SE, Malenka RC, Nestler EJ (2006) Neural mechanisms of addiction: the role of reward-related learning and memory. Annu Rev Neurosci 29:565-598. CrossRef Medline

Kirchhausen T, Macia E, Pelish HE (2008) Use of dynasore, the small molecule inhibitor of dynamin, in the regulation of endocytosis. Methods Enzymol 438:77-93. CrossRef Medline

Kristensen AS, Andersen J, Jørgensen TN, Sørensen L, Eriksen J, Loland CJ, Strømgaard K, Gether U (2011) SLC6 neurotransmitter transporters: structure, function, and regulation. Pharmacol Rev 63:585-640. CrossRef Medline

Loder MK, Melikian HE (2003) The dopamine transporter constitutively internalizes and recycles in a protein kinase $\mathrm{C}$-regulated manner in stably transfected PC12 cell lines. J Biol Chem 278:22168-22174. CrossRef Medline

Lyon GJ, Abi-Dargham A, Moore H, Lieberman JA, Javitch JA, Sulzer D (2011) Presynaptic regulation of dopamine transmission in schizophrenia. Schizophr Bull 37:108-117. CrossRef Medline

Macia E, Ehrlich M, Massol R, Boucrot E, Brunner C, Kirchhausen T (2006) Dynasore, a cell-permeable inhibitor of dynamin. Dev Cell 10:839-850. CrossRef Medline

Mazei-Robison MS, Blakely RD (2005) Expression studies of naturally occurring human dopamine transporter variants identifies a novel state of transporter inactivation associated with Val382Ala. Neuropharmacology 49:737-749. CrossRef Medline

Mazei-Robison MS, Bowton E, Holy M, Schmudermaier M, Freissmuth M, Sitte HH, Galli A, Blakely RD (2008) Anomalous dopamine release associated with a human dopamine transporter coding variant. J Neurosci 28:7040-7046. CrossRef Medline

Melikian HE (2004) Neurotransmitter transporter trafficking: endocytosis, recycling, and regulation. Pharmacol Ther 104:17-27. CrossRef Medline 
Melikian HE, Buckley KM (1999) Membrane trafficking regulates the activity of the human dopamine transporter. J Neurosci 19:7699-7710. Medline

Menon M, Schafer DA (2013) Dynamin: expanding its scope to the cytoskeleton. Int Rev Cell Mol Biol 302:187-219. CrossRef Medline

Miranda M, Sorkina T, Grammatopoulos TN, Zawada WM, Sorkin A (2004) Multiple molecular determinants in the carboxyl terminus regulate dopamine transporter export from endoplasmic reticulum. J Biol Chem 279: 30760-30770. CrossRef Medline

Miranda M, Wu CC, Sorkina T, Korstjens DR, Sorkin A (2005) Enhanced ubiquitylation and accelerated degradation of the dopamine transporter mediated by protein kinase C. J Biol Chem 280:35617-35624. CrossRef Medline

Miranda M, Dionne KR, Sorkina T, Sorkin A (2007) Three ubiquitin conjugation sites in the $\mathrm{N}$ terminus of the dopamine transporter mediate protein kinase C-dependent endocytosis of the transporter. Mol Biol Cell 18:313-323. Medline

Navaroli DM, Stevens ZH, Uzelac Z, Gabriel L, King MJ, Lifshitz LM, Sitte HH, Melikian HE (2011) The plasma membrane-associated GTPase Rin interacts with the dopamine transporter and is required for protein kinase C-regulated dopamine transporter trafficking. J Neurosci 31: 13758-13770. CrossRef Medline

Navaroli DM, Bellvé KD, Standley C, Lifshitz LM, Cardia J, Lambright D, Leonard D, Fogarty KE, Corvera S (2012) Rabenosyn-5 defines the fate of the transferrin receptor following clathrin-mediated endocytosis. Proc Natl Acad Sci U S A 109:E471-E480. CrossRef Medline

Opazo F, Schulz JB, Falkenburger BH (2010) PKC links gq-coupled receptors to DAT-mediated dopamine release. J Neurochem 114:587-596. CrossRef Medline

Puthenveedu MA, Lauffer B, Temkin P, Vistein R, Carlton P, Thorn K, Taunton J, Weiner OD, Parton RG, von Zastrow M (2010) Sequencedependent sorting of recycling proteins by actin-stabilized endosomal microdomains. Cell 143:761-773. CrossRef Medline

Rao A, Simmons D, Sorkin A (2011) Differential subcellular distribution of endosomal compartments and the dopamine transporter in dopaminergic neurons. Mol Cell Neurosci 46:148-158. CrossRef Medline

Rao A, Richards TL, Simmons D, Zahniser NR, Sorkin A (2012) Epitopetagged dopamine transporter knock-in mice reveal rapid endocytic trafficking and filopodia targeting of the transporter in dopaminergic axons. FASEB J 26:1921-1933. CrossRef Medline

Sakrikar D, Mazei-Robison MS, Mergy MA, Richtand NW, Han Q, Hamilton PJ, Bowton E, Galli A, Veenstra-Vanderweele J, Gill M, Blakely RD (2012) Attention deficit/hyperactivity disorder-derived coding variation in the dopamine transporter disrupts microdomain targeting and trafficking regulation. J Neurosci 32:5385-5397. CrossRef Medline

Sankaranarayanan S, Ryan TA (2001) Calcium accelerates endocytosis of vSNAREs at hippocampal synapses. Nat Neurosci 4:129-136. CrossRef Medline

Saunders C, Ferrer JV, Shi L, Chen J, Merrill G, Lamb ME, Leeb-Lundberg LM, Carvelli L, Javitch JA, Galli A (2000) Amphetamine-induced loss of human dopamine transporter activity: an internalization-dependent and cocaine-sensitive mechanism. Proc Natl Acad Sci U S A 97:6850-6855. CrossRef Medline

Schafer DA (2004) Regulating actin dynamics at membranes: a focus on dynamin. Traffic 5:463-469. CrossRef Medline

Shaner NC, Campbell RE, Steinbach PA, Giepmans BN, Palmer AE, Tsien RY (2004) Improved monomeric red, orange and yellow fluorescent proteins derived from discosoma sp. red fluorescent protein. Nat Biotechnol 22:1567-1572. CrossRef Medline

Sorkina T, Doolen S, Galperin E, Zahniser NR, Sorkin A (2003) Oligomerization of dopamine transporters visualized in living cells by fluorescence resonance energy transfer microscopy. J Biol Chem 278:28274-28283. CrossRef Medline

Sorkina T, Hoover BR, Zahniser NR, Sorkin A (2005) Constitutive and protein kinase $\mathrm{C}$-induced internalization of the dopamine transporter is mediated by a clathrin-dependent mechanism. Traffic 6:157-170. CrossRef Medline

Sorkina T, Miranda M, Dionne KR, Hoover BR, Zahniser NR, Sorkin A (2006) RNA interference screen reveals an essential role of Nedd4-2 in dopamine transporter ubiquitination and endocytosis. J Neurosci 26 : 8195-8205. CrossRef Medline

Sorkina T, Richards TL, Rao A, Zahniser NR, Sorkin A (2009) Negative regulation of dopamine transporter endocytosis by membrane-proximal N-terminal residues. J Neurosci 29:1361-1374. CrossRef Medline

Sorkina T, Caltagarone J, Sorkin A (2013) Flotillins regulate membrane mobility of the dopamine transporter but are not required for its protein kinase C dependent endocytosis. Traffic 14:709-724. CrossRef Medline

Steinkellner T, Yang JW, Montgomery TR, Chen WQ, Winkler MT, Sucic S, Lubec G, Freissmuth M, Elgersma Y, Sitte HH, Kudlacek O (2012) $\mathrm{Ca}(2+) /$ calmodulin-dependent protein kinase IIalpha (alphaCaMKII) controls the activity of the dopamine transporter: implications for Angelman syndrome. J Biol Chem 287:29627-29635. CrossRef Medline

St Pierre CA, Leonard D, Corvera S, Kurt-Jones EA, Finberg RW (2011) Antibodies to cell surface proteins redirect intracellular trafficking pathways. Exp Mol Pathol 91:723-732. CrossRef Medline

Tampellini D, Magrané J, Takahashi RH, Li F, Lin MT, Almeida CG, Gouras GK (2007) Internalized antibodies to the Abeta domain of APP reduce neuronal Abeta and protect against synaptic alterations. J Biol Chem 282:18895-18906. CrossRef Medline

Thomsen M, Han DD, Gu HH, Caine SB (2009) Lack of cocaine selfadministration in mice expressing a cocaine-insensitive dopamine transporter. J Pharmacol Exp Ther 331:204-211. CrossRef Medline

Tilley MR, O’Neill B, Han DD, Gu HH (2009) Cocaine does not produce reward in absence of dopamine transporter inhibition. Neuroreport 20: 9-12. CrossRef Medline

Torres GE, Gainetdinov RR, Caron MG (2003) Plasma membrane monoamine transporters: structure, regulation and function. Nat Rev Neurosci 4:13-25. CrossRef Medline

Zahniser NR, Sorkin A (2004) Rapid regulation of the dopamine transporter: role in stimulant addiction? Neuropharmacology 47:80-91. CrossRef Medline 